\title{
24
}

\section{Writing-to-Learn in First-Year Biological Sciences}

\author{
Cynthia Paszkowski \& Margaret Haag \\ University of Alberta
}

In 2006-2007, we established a writing exercise in two large first-year biology courses. Overall, our exercise, which consisted of multiple drafts of a 500-word essay, offered students a good introduction to how editorial feedback can improve content and style in scientific writing. We discuss our goals, procedures, outcome, and students' responses to our initiative.

\section{Introduction}

$\mathrm{E}$ dward O. Wilson is one of world's foremost evolutionary biologists. He is also a distinguished author whose books have won the Pulitzer Prize for General Nonfiction. In his autobiography, Naturalist, Wilson (1994) described how, as a young professor, he nurtured his ideas concerning biological diversity:

They then turned into narratives, which I began to repeat to myself like stories. I prepared to speak about the matter to others. I imagined how the narrative would look in print, how it might sound in a lecture before a skeptical audience. I rehearsed, edited, and performed in silence. I was a storyteller, sorting and arranging pieces of nonfiction, dreaming in order to fill in the gaps. Then I tried the performance before a real audience. (p. 206)
The Department of Biological Sciences at the University of Alberta offers two introductory courses, Biology 107 (Introduction to Cell Biology) and Biology 108 (Introduction to Biodiversity), with a combined enrollment of nearly 3,000 undergraduates each academic year. These courses include a lecture, laboratory, and seminar component. The student population is diverse, including science, arts, education, and pre-professional students. In Winter 2006, inspired by a university-wide initiative to encourage writing within courses across disciplines and to improve the writing skills of students in our own honors and specialization programs, we decided to change the seminar component of the introductory courses from review-based tutorials to writing workshops. Developing and delivering a relevant writing exercise to 600 to 900 students simultaneously offered a variety of logistic challenges. These included ensuring access to reading materials, standardization of instruction and grading, and expeditious handling 
of multiple drafts. Still, we felt our efforts would be well invested and that we might teach students to be effective scientific storytellers.

In developing this initiative, we reviewed and assessed a number of models for integrating writing into diverse curricula (Young \& Fulwiler, 1986; Fulwiler \& Young, 1990). Our specific goals in Biology 107 and 108 were to: 1) demonstrate that writing can aid in mastery of key concepts in biology; 2) encourage critical thinking; 3) improve communication skills; 4) demonstrate the importance of clear, concise writing in biology; and 5) introduce the use of multiple drafts to improve writing and understanding. We also used the workshops as opportunities to train 28 biology graduate-students in directing and assessing written work. Graduate students were active participants in developing and defining all aspects of the writing assignments. Each was responsible for 74 to 148 under-graduate students.

\section{Our Approach}

The remainder of this essay discusses our results and experiences during the winter term, January - April 2007. In this term, students in both courses were asked to produce three drafts of a 500-word essay based on a reading in American Scientist. These readings were related to material and concepts covered in each course but neither topic was addressed directly in lecture or lab. In Biology 107 the reading was on type-A avian influenza. The Biology 108 reading was on global declines in amphibian populations. The essay was worth $10 \%$ of the grade in each course, with $60 \%$ of the essay grade devoted to biological content. Students were guided in the writing process through attending five 50-minute workshops (class size 34 to 74 ) and through detailed assessment rubrics.

Figure 1 summarizes the undergraduate student experience in our writing initiative; Figure 2 does the same for the graduate teaching assistants. Near the end of the course, but before students received the marks and comments on their final drafts, we administered an evaluation form comprised of 15 multiple-response questions and requests for written comments as well.

\section{Outcomes}

On our evaluation forms, many students, $61.3 \%$ in Biology 107 ( $\mathrm{n}=618$ responses) and 67.4\% in Biology 108 ( $n=608$ responses), stated that prior to the assignment they felt their ability to write an effective scientific essay was "good," "very good," or "excellent." After completing the writing assignment, 59.3\% in Biology 107 and 54.7\% in Biology 108 responded positively that the assignment proved "somewhat useful," "useful," or "very useful" in improving their ability to write a scientific essay. Production of multiple drafts definitely aided students in improving their essays. Of students who completed both graded drafts, 81.1\% in Biology $107(\mathrm{n}=667)$ and 93.6\% in Biology $108(n=626)$ achieved higher scores on the final draft. Average numerical scores between second and third drafts increased by 12.3\% in Biology 107 and $17.4 \%$ in Biology 108 . Only $17.1 \%$ of students in Biology 107 and 13.1\% in Biology 108 felt that they did not receive sufficient comments from their instructors to improve their final essay.

Written comments on the evaluation forms offered the clearest picture of aspects of the assignment that offered students the greatest challenges and that required the most improvement. Comments were consistent with categorical responses on the evaluation forms and further developed themes contained there. An example of a challenge highlighted by student comments was the restricted length of the essay at 500 words. Students felt that their essays would have been stronger if they could have been longer. In fact, a short essay was a deliberate choice on our part. We did not want under-graduate student writers and graduate student graders to become "overwhelmed" by the assignment. Also, conciseness is a hallmark of scientific writing. More is not better, and strict limits are often imposed on commonly produced documents such as abstracts and proposals. We decided to make future essay topics more focused so that the 500-word limit offered a better fit to the skills and previous experience of our students.

We found that a first step towards this goal was to choose readings that can serve as effective cornerstones for essays. Readings must be at the right level of difficulty, assumed background knowledge, 


\section{Figure 1}

This flow chart describes the activities of first-year students in our writing-to-learn initiative, Department of Biological Sciences, University of Alberta.

\section{Undergraduate Experience}

Establishing the "Writing to Learn" philosophy

Visit by Prof. to discuss research and education

Visit serves as topic for low-risk writing (free-write)

Introduction to assignment

Objectives

Question

Resources

Articles

Assessment rubric

Appropriate background information on topic

Assign first draft

Out of Class: Students prepare first draft

Review of first draft

Group discussion: Critique sample paragraph

Paired peer review

Reading aloud

Written comments

Group discussion: Summary of common problems

Out of Class: Students prepare second draft

Students submit second draft for evaluation

- Submission includes peer reviewed first draft

- Critical assessment of biological content (60\%)

- Critical assessment of written communication skill (40\%)

Students receive assessment of second draft

Group discussion: Common errors

Handout of guidelines for improvement

Out of Class: Students prepare third (final) draft

Students submit third draft for evaluation

Submission includes marked second draft

Critical assessment of content and communication skills

Critical assessment of incorporation of feedback

Students asked to evaluate "Writing to Learn" exercise

Students receive assessment of third draft 


\section{Figure 2}

Flow chart describing the activities of graduate teaching assistants who acted as instructors in our writing-to-learn initiative, Department of Biological Sciences, University of Alberta.

\section{Teaching Assistant Experience}

1. Pre-session training

- Attend University Writing Task Force workshops

- Attend course-specific writing workshops

\section{Prepare for assessment}

- Group marking of sample essays

- Discussion of application of marking rubric

- Establish guidelines for assessing plagiarism

\section{Course delivery}

- Small group seminars

- 2 seminars - preparation for written assignment (background, free-write, peer review, critique)

- 1 seminar - return second draft (review assessment scheme, guidelines for improvement)

- Individual discussions with students 
and information content. We then compose questions and guidelines that direct, but do not dictate content. For example, "Discuss how two socio-political factors affect the spread of type-A influenza (2 of 10 marks)." Delimiting the number of factors and assigning a weight indicate how much of the essay should be dedicated to this discussion, but each student chooses which examples to use. Likewise, such focused directions require that students not only extract information from the reading, but understand, distill and apply it. Our essay topics all require the integration, not just reportage, of scientific evidence to support an argument or conclusion. We strongly encourage students to use only the assigned reading and their textbook to compose the essay so that they do not become distracted by extraneous material that is frequently too technical for them to appreciate as beginning biologists.

At least some students found it difficult to follow and implement suggestions and editing by the teaching assistants. To improve students' understanding of the editorial process, we formalized peer review and students must now hand in peer-edited first drafts. To aid with revisions of the second draft, we looked for methods to enable instructors to provide more directed guidance (Hodges, 1997). Teaching assistants now segregate their comments on style versus comments on content, e.g. style in the left margin, content in the right. Also, we encourage instructors to be more positive by consciously highlighting something "good" about each essay. Many first-year university students are not accustomed to receiving and responding to extensive and pointed criticism of written assignments, particularly the blunt and questioning comments that typify reviews produced by scientists.

From the start, preparatory sessions with graduate teaching assistants covered the mechanics of writing the essay, the background reading, and its relationship to the assigned essay. The area where teaching assistants needed the most guidance was the application of the marking rubric as a means of ensuring fair and consistent assessment across multiple drafts. Most instructors were unfamiliar with rubrics. We discovered that the best way to demonstrate the role of the rubric was to have a group of teaching assistants use it to assess a common set of student essays. A discussion followed on expectations for student performance and how to assign marks based on the rubric's pre-existing framework. For the final draft of the essay, the rubric awarded marks for how successfully the student applied the instructor's feedback. This feature allowed teaching assistants to evaluate students' individual progress through various stages of the writing process. One assessment criterion contained in the rubrics of both the second and final draft stated: "Using his/her own words, the student communicates key ideas and information." This criterion encouraged students to produce original writing and provided instructors with a mechanism to deal with some aspects of plagiarism.

\section{Conclusions}

We believe that we have taken the first steps toward establishing a culture in our department where writing is acknowledged as a necessary skill for a successful, satisfying career in science as well as other professional endeavors. Biology 107 and 108 are part of a suite of first- and second-year core courses taken by most biology majors and all specialization and honors students; now these incoming students will all experience dedicated writing-workshops twice, along with long-established lectures and laboratories. We are working to make our exercises and rubrics more effective, and thus demonstrate that good writing has a place in biology. We hope to make students see that writing can contribute to their understanding and appreciation of information. If great data and novel ideas are not woven into convincing, well-crafted stories, they rarely receive the recognition that they deserve, nor do their creators.

\section{Acknowledgements}

This initiative was funded by the University of Alberta Department of Biological Sciences and Teaching and Learning Enhancement Fund. Alissa Moenting assisted with manuscript preparation. This essay benefited from comments provided by three anonymous reviewers. 


\section{References}

Fulwiler, T., \& Young, A. (1990). Programs that work: Models and methods for writing across the curriculum. Portsmouth: Boynton/Cook Publishers.

Wilson, E. O. (1994). Naturalist. Washington, DC: Island Press.

Hodges, E. (1997). Negotiating the margins: Some principles for responding to our students' writing, some strategies for helping students read our comment. In M. D. Sorcinelli \& P. Elbow (Eds.), Writing to learn: Strategies for assigning and responding to writing across the disciplines (pp. 77-92). San Francisco: JosseyBass Publishers.

Young, A., \& Fulwiler, T. (1986). Writing across the disciplines: Research into practice. Portsmouth: Boynton/Cook Publishers. 